\title{
Para além da Educação a Distância: Práticas Formativas e Relacionais em um Curso de Ciências Biológicas
}

\section{Germana Costa Paixão*1, Ana Ciléia Pinto Teixeira Henriques², Francisco Fábio Castelo Branco ${ }^{3}$, Eloisa Maia Vidal ${ }^{4}$}

${ }^{1}$ Coordenadora do Curso de Ciências Biológicas EAD/UAB/Universidade Estadual do Ceará, Vice-Líder do Grupo de Pesquisa Tecnologias Educacionais e Educação a distância. Av. Dr. Silas Munguba, 1700 Fortaleza - Ceará - Brasil. germana.paixao@uece.br

2 Tutora de pesquisa, Curso de Ciências Biológicas EAD/UAB/Universidade Estadual do Ceará, Av. Dr. Silas Munguba, 1700 - Fortaleza - Ceará - Brasil. anacileia.henriques@uece.br

${ }^{3}$ Coordenador geral UAB/UECE, Secretaria de Apoio a Tecnologias Educacionais- Universidade Estadual do Ceará, Av. Dr. Silas Munguba, 1700 - Fortaleza - Ceará - Brasil. ffcastelo@terra.com.br

4 Coordenadora Adjunta UAB/UECE, Curso de Física /Universidade Estadual do Ceará, Av. Dr. Silas Munguba, 1700 - Fortaleza - Ceará - Brasil. eloisamvidal@yahoo.com.br

\section{Resumo}

As práticas de formação que incentivam o desenvolvimento das habilidades afetivas em estudantes têm sido avaliadas no contexto de ensino a distância no Brasil. O estudo tem como objetivo apresentar práticas formativas e relacionais desenvolvidas no curso de Ciências Biológicas na modalidade a distância de uma universidade estadual no Ceará. É um estudo descritivo-reflexivo em forma de estudo de caso que discute experiências em andamento, sendo estas: Monitoria Acadêmica; Vida em Foco; Ciência na Escola e Musicalizando a Biologia. As atividades têm procurado desenvolver nos alunos o espírito de colaboração e da experiência de realidade em que, em um curto espaço de tempo, estarão inseridos. Acredita-se que, dessa forma, se permite um ensino mais crítico e reflexivo, no qual novas ferramentas são oportunizadas e que podem romper a hierarquia ainda persistente entre professores e alunos.

Palavras-chave: Ensino; Atitude; Educação a distância; Educação superior; Tecnologia da educação. 


\title{
Beyond the Distance Education: Formation and Relational Practice in a Biological Sciences Course
}

\begin{abstract}
Training practices that encourage the development of affective skills in students have been valued in the context of distance learning (DL) in Brazil. The study aims to provide formative and relational practices developed in the course of Biological Sciences in the distance mode of a state university in Ceara. It is descriptive-reflective research in the form of case study that discusses the following ongoing experiments: Academic Monitoring; Life in Focus; Science in School and 'Musicalizing' Biology. The activities have sought to develop in students the spirit of collaboration and the experience of reality in which they, in a short time, will be placed. It is believed that this way allows more critical and reflective teaching, in which new tools become available for DL that will break the persistent hierarchy between teachers and students.
\end{abstract}

Keywords: Teaching; Attitude; Distance education; Higher education; Education technology. 


\section{Introdução}

A Educação a Distância (EaD) assume importante magnitude no contexto educacional brasileiro, considerando, principalmente, a necessidade cada vez mais urgente da formação de profissionais de diversas áreas com qualidade e eficiência.

Freitas e Sousa (2013) discutem que, diante dos avanços tecnológicos, esta modalidade de educação, que exige a utilização de tecnologias para que o processo de ensino-aprendizagem ocorra, expande-se nos diversos níveis de ensino, em particular no ensino superior.

Visto que a característica principal dessa modalidade de educação é a separação espacial e temporal entre professor e aluno, mas, mesmo não estando juntos, estes estão em contato mediados por tecnologias, discute-se como esta mediação pode influenciar no desenvolvimento dos processos relacionais que, a princípio, se estabeleceriam apenas com a presença física destes atores do processo ensinoaprendizagem.

Vergara (2007) discute que a pedagogia destaca a importância do relacionamento professor/aluno na construção do indivíduo e da sociedade da qual ele faz parte e afirma que não é raro se ver tal questão como uma das limitações da EaD e, portanto, com potencial para mitigar seu valor.

Somada a essa questão, Valente (2003) pondera que o que tem sido proposto, em grande parte, em contextos de EaD, pode ser considerado como uma imitação das abordagens tradicionais de ensino, viabilizadas, porém, por meio de recursos tecnológicos digitais, o que leva ao questionamento quanto à qualidade do ensino e o impacto no processo e resultados da aprendizagem do aluno, contribuindo ainda mais fortemente para questionamentos quanto à modalidade EaD.

A tecnologia, embora chave na compreensão do processo de práticas de EaD, deve ser entendida, conforme afirma Sousa (2011, p.171), "como uma objetivação das relações sociais que comanda e fecunda qualquer sociedade, não sendo esta autônoma e apartada daqueles que a geram, isto é, do próprio homem, da sociedade. A tecnologia é uma invenção humana". 
Freitas e Sousa (2013) defendem a valorização da mediação, compreendida esta sob o olhar da abordagem histórico-cultural que, em linhas gerais, concebe o sujeito como um ser ativo, cujas aprendizagens são construídas na interação com o objeto e com outros seres sociais.

Vergara (2007) reforça que a aprendizagem é uma atividade socialmente construída, pois, embora o indivíduo dê o "salto" pela reflexão, este precisa da relação com autores diversos, colegas, professores, tutores e outras pessoas que façam parte de sua rede de relações.

Embora se enfatize fortemente a necessidade de valorização da construção autônoma do aluno, dependente da vontade deste estudar, pesquisar e produzir de forma independente e disciplinada, compreende-se que esta modalidade educacional se fortalece, por meio de múltiplas atividades, através da aprendizagem colaborativa, com a troca de informações entre alunos (Maia \& Meirelles, 2002).

Fundamentando-se na urgente necessidade de novas práticas formativas, que estimulem interações para além do desenvolvimento de habilidades cognitivas, mas que envolvam também aspectos afetivos nos contextos de EaD, novas propostas têm sido desenvolvidas em cursos de graduação nesta modalidade, buscando "o algo mais", que possa tornar ainda mais atrativa a entrada (e a permanência) do aluno na EaD.

Imbuídos desta motivação, este trabalho visa relatar ações e experiências do curso de licenciatura Ciências Biológicas EaD da Universidade Estadual no Ceará-UECE em parceria com a Universidade Aberta do Brasil-UAB, refletindo sobre as práticas que visam à formação de competências relacionais entre os atores envolvidos neste contexto.

Trata-se de estudo de cunho descritivo-reflexivo, na modalidade estudo de caso, o qual se baseia no relato das ações desenvolvidas no curso, adicionais ao contexto do Ambiente Virtual de Aprendizagem (AVA) no qual se desenvolvem as atividades componentes do curso de Licenciatura em Ciências Biológicas EaD.

São descritas neste trabalho as atividades realizadas pelo curso, discutindo-se a implicação das mesmas para formação docente e para o desenvolvimento de habilidades afetivas, sendo estas referentes à internalização de emoções, interesses, 
crenças e atitudes, os quais são essenciais para a formação do professor (Bastable, 2010).

Optou-se por esta abordagem metodológica visto que, segundo Sampieri, Colado e Lucio (2013), os estudos de caso propõem-se a analisar profundamente uma unidade para responder à formulação de um problema, testar hipóteses ou desenvolver uma teoria.

Neste caso, a unidade de análise é o curso de Ciências Biológicas na modalidade EaD (BioEaD) e o problema formulado consiste na descrição de estratégias desenvolvidas no curso que tenham como fundamento teórico-pedagógico a valorização de práticas relacionais associadas às formativas.

\section{Elementos da investigação}

Embora o curso apresente uma trajetória permeada por diversas atividades que buscam desenvolver no discente a autonomia, motivando a interação entre os atores diversos da EaD e inserindo-o em espaços além dos AVA, para este estudo optou-se por detalhar quatro iniciativas que mais se aproximam da proposta de estímulo de colaboração entre os alunos e professores, sendo estas descritas:

\subsection{Projeto Monitoria Acadêmica}

Nesta atividade, o objetivo central é capacitar o aluno monitor quanto às estratégias pedagógicas que serão utilizadas ao longo da monitoria acadêmica das disciplinas diretamente vinculadas à área de estudos de "Biologia Geral" do Curso de Ciências Biológicas na modalidade EaD.

Trata-se de iniciativa pioneira na institucionalização dos alunos da modalidade EaD na Universidade Estadual do Ceará, pois pela primeira vez os mesmos puderam se inscrever e concorrer ao Edital público de seleção de monitores lançado anualmente pela Pró-Reitoria de Graduação-PROGRAD.

Foram selecionados três alunos monitores que atuarão nas turmas em funcionamento nos polos de Beberibe, Aracoiaba e Maranguape, todos no Ceará. A função desses monitores será auxiliar os discentes por meio de grupos de estudos, 
fichamentos de artigos científicos, produção de modelos e jogos didáticos envolvendo temáticas relevantes com vistas à aplicação nas comunidades.

Além disso, participarão também do desenvolvimento de atividades lúdicas como elaboração de cordéis e paródias abrangendo as principais doenças que atingem a comunidade local, como forma de contribuir para as práticas de educação em saúde e contemplar ações de extensão para a população do entorno da Universidade.

Considera-se que, com essa atuação, a figura do monitor será importante como suporte de comunicação entre alunos e professor, agindo, portanto, como um mediador.

Segundo Lopes (2005), a Monitoria Acadêmica, pelas suas características e abrangência, constitui-se em uma proposta que auxilia o professor em suas atividades cotidianas de forma expressiva em todas as etapas do processo pedagógico. Ao mesmo tempo, proporciona ao aluno a possibilidade de ampliar o conhecimento em certa disciplina, despertar o interesse para a docência e desenvolver aptidões e habilidades no campo do ensino, sendo, portanto, de fundamental importância no processo formativo.

\subsection{Projeto Vida em Foco}

Esta ação visa compartilhar, através de um programa de rádio, conteúdos de qualidade e voltados para as diversas temáticas existentes na Biologia, de maneira dinâmica e que atinja um público diversificado.

O uso de recursos de áudio que facilitem a transmissão de conhecimentos, a adaptação de processos educativos com uso do rádio, além da possível constituição de um espaço que mostre a capacidade criativa do aluno são vantagens oferecidas pela ferramenta utilizada para a realização do projeto em questão.

Compreendendo a importância do rádio para o processo de ensino-aprendizagem e para a comunicação entre alunos e professores, será utilizado um espaço no Programa de Rádio 'Revolução do Amor' para a aplicação do projeto "Vida em Foco", que terá função educativa e social, levando informações para pessoas de todos os níveis e intelectos. 
O público-alvo serão ouvintes dos trinta e oito municípios alcançados pela rádio Litoral AM 1110 kwhertz, cuja base fica no município de Beberibe/CE, e internautas que acessem o site www.litoralam.com e estejam interessadas em aprender sobre biologia, suas curiosidades, tirar dúvidas e fazer revisões.

As atividades envolvem, além da pesquisa e do estímulo ao aprofundamento dos estudos, a expressão de sentimentos, crenças e atitudes diante de conteúdos da formação dos acadêmicos, que devem ser compartilhados com a população geral de forma clara e objetiva, otimizando a divulgação do conhecimento.

Considera-se que a promoção de conhecimento é de grande valia, sendo esta uma oportunidade de mostrar a realidade do estudante universitário de biologia ao grande público. Além disso, é uma maneira de divulgar e atrair alunos para o curso de licenciatura em Ciências Biológicas na modalidade EaD ofertado pela Universidade Estadual do Ceará em parceria com a Universidade Aberta do Brasil.

\subsection{Projeto Ciências na Escola}

Esta ação envolve a visita às escolas da rede pública do polo do município de Maranguape, localizado na região metropolitana de Fortaleza/CE para identificação das demandas docentes e discentes de aulas práticas no ensino de Ciências e, posteriormente, a elaboração dos planos de aula, levantamento dos materiais necessários e execução destas aulas práticas pelos próprios acadêmicos, orientados pelo professor, para que os mesmos vivenciem a realidade docente no ensino público e possam refletir sobre as demandas de formação aos quais os mesmos vivenciam.

Além do processo de construção, será considerado também o processo de avaliação, no qual cada grupo de graduandos, responsável por determinada prática, a registrará em forma de relatório para que sua eficácia seja avaliada. As práticas que gerarem bons frutos deverão ser repetidas em outro momento, as que não forem bem executadas deverão ser melhoradas e as que não resultarem em boas contribuições deverão ser descartadas. 


\subsection{Projeto Musicalizando a Biologia}

Esta ação visa à produção de paródias que abordem os conteúdos programáticos previstos pelos Parâmetros Curriculares Nacionais para o Ensino Fundamental (PCNEF) e para o Ensino Médio (PCNEM), visando à introdução de conceitos básicos sobre as mais diversas temáticas que envolvem o estudo de Ciências e Biologia, sendo estas apresentadas posteriormente em escolas da rede pública dos municípios próximos ao polo do curso.

A música, proposta como recurso didático por Fröebel (1810) e desde então passível de ser utilizada para favorecer a aprendizagem significativa, alia aspectos lúdicos e cognitivos e possibilita ao aluno maior aproximação com o tema a ser estudado (Barros et al 2013; Bertocello \& Santos, 2002). Segundo Ribas e Guimarães (2004), para alcançar uma educação inteligente e proveitosa, a aprendizagem deve ser desenvolvida de uma forma prazerosa para gerar motivação e estímulo. Nesse contexto, a música satisfaz esse critério, pois desperta a atenção e reflexão, favorece a visão crítica e auxilia na construção de conhecimentos significativos.

Segundo Silveira e Kiouranis (2008), as músicas e suas letras podem ser uma importante alternativa para estreitar o diálogo entre alunos, professores e conhecimento científico, uma vez que abordam temáticas com grande potencial de problematização que estão presentes de forma significativa na vida do aluno.

Como forma de tornar atrativas as paródias produzidas, serão escolhidas melodias de músicas populares e atrativas aos jovens que estejam na faixa etária correspondente às turmas de ensino fundamental e médio, nas quais serão executadas as produções e serão gravadas em forma de áudio e vídeo e disponibilizadas em canal do Youtube ${ }^{\circledR}$.

\section{Definição do alcance do trabalho, relevância do resultado produzido e seu aporte a realidade nacional, regional ou local}

Acredita-se que estas ações contribuam para a formação do acadêmico, propiciando vivência prática e o estabelecimento de relações que necessitarão ser fundamentadas e aprimoradas em sua prática profissional docente, fomentando, dessa 
maneira, a formação de uma nova classe de profissionais, mais críticos, reflexivos e cientes da realidade à qual deverão se remeter.

Concordando com Vergara (2007), compreende-se que, para alcançar os objetivos específicos de um processo educacional, relacionamentos em educação têm contornos particulares, devendo facilitar para o aluno condições que Ihe permitam aprender a questionar, a dialogar, a refletir, a criticar, a aprender, o que se considera ser alcançado através destas estratégias.

A autora ainda acrescenta que, dado que não se pode falar de ensino dissociado de aprendizagem, relacionamentos em EaD devem provocar a curiosidade no aluno e criar-Ihe oportunidades para o fortalecimento de habilidades sociais na interação fecunda com outras pessoas (Vergara, 2007).

Nunes, Franco e Silva (2010) reforçam essa discussão relembrando que, em meados da década de 1970, o construtivismo de Jean Piaget agregou à compreensão de uma abordagem pedagógica de interação à necessidade de construir um aprendizado novo, baseado nas interações sociais, onde o "eu" se transforma no "nós", onde as operações dão lugar à cooperação.

Dessa forma, práticas que valorizem os aspectos relacionais como as mencionadas consideram a mediação pedagógica e tornam o conhecimento acessível ao público leigo, possivelmente contribuindo para a motivação deste ao acesso à educação.

\section{Conclusões}

Longe de traçar propostas de atuação, o estudo visou apresentar estratégias de trabalho desenvolvidas em nossa realidade, tais como a monitoria acadêmica, o uso de spots de rádio para divulgação de ações em saúde e temáticas ligadas à biologia, a produção de paródias com conteúdos científicos e a ministração de aulas de ciências nas escolas, pautadas em fundamentos pedagógicos que valorizam a interação e a dialogicidade, assim como, o rompimento da hierarquia professor-aluno, considerando ambos os atores do processo educativo através da importância de novas ferramentas na EaD. 


\section{Agradecimentos}

Agradecemos o apoio financeiro da Universidade Aberta do Brasil que fomenta a oferta do Curso de Ciências Biológicas EAD da Universidade Estadual do Ceará.

\section{Referências bibliográficas}

Bastable, S.B. (2010). O Enfermeiro como Educador: princípios de ensinoaprendizagem para a prática de enfermagem (3. ed.). Porto Alegre: Artmed.

Barros, M. D. M.; Zanella, P. G.; Araujo-Jorge T. C. (2013) A música pode ser uma estratégia para o ensino de ciências naturais? Analisando concepções de professores da educação básica. Revista Ensaio, v.15, n. 01, p. 81-94.

Bertoncello, L.; Santos, M.R. (2002) Música aplicada ao ensino da informática em ensino profissionalizante. Iniciação Científica CESUMAR, v. 4, n. 2, p. 131-142.

Freitas, L.G., Sousa, CAM. (2013). Mediação pedagógica na educação a distância: as pesquisas brasileiras. Linhas Críticas, 19 (40), 523-542.

Lopes, G.T. (2005) O desenvolvimento da monitoria acadêmica na Universidade do Estado do Rio de Janeiro: período 1985-2004. Relatório de Pesquisa. Rio de Janeiro (RJ): FENF/UERJ; 2005.

Maia, M. C., Meirelles, F. S. (2002) Educação a distância: o caso da Open University. RAE Eletrônica, 1(1),1-15.

Nunes, T.W.N., Franco, S.R.K., Silva, V.D. (2010) Como a educação a distância pode contribuir para uma prática integral em saúde? Revista Brasileira de Educação Médica, 34 (4), 554-564.

Ribas, L.C.C.; Guimarães, L.B. (2004) Cantando o mundo vivo: aprendendo biologia no pop rock brasileiro. Ciência e Ensino, Campinas, n.12.

Sampieri, R.H., Collado, C.F., Lucio, M.P.B. (2013). Metodologia de Pesquisa. Porto Alegre: Penso. 
Silveira, M. P.; Kiouranis, N. M. M. (2008) A música e o ensino de química. Química nova na escola. São Paulo, n.28, p.28-31.

Sousa, C.A.M. (2011). Novas Linguagens e Sociabilidades: como uma juventude vê novas tecnologias. Revista Interacções. 7(17), 170-188.

Valente, J.A. (2003). Educação a distância no ensino superior: soluções e flexibilizações. Comunicação, Saúde, Educação, 7(12),139-142.

Vergara, S.C. (2007). Estreitando relacionamentos na educação a distância. Cadernos EBAPE.BR, 5, 1-8. 